\title{
REPRESENTAÇÕES SOBRE A IMAGEM NA APRENDIZAGEM GEOGRÁFICA
}

\author{
Maria Fernanda Alegria ${ }^{1}$
}

\begin{abstract}
Resumo - À palavra «imagem» associa-se um sem número de representações. Considerando a triologia autor-obra-público, o estudo dos dois primeiros tem sido mais valorizado, embora recentemente a recepção das mensagens visuais tenha ganho fôlego. Todas as mensagens estão sujeitas a interpretações diversas mas essa polissemia é sobretudo atributo da imagem. Qualquer imagem é uma analogia do real, uma sua representação, tão «natural» para alguns que semelhança e identidade se confundem. Para evitar essa falsa sobreposição há que passar do simples reconhecimento à interpretação. Para a interpretação concorrem vários factores, uns facilmente detectáveis, outros mais obscuros. Entre estes está o hábito de observar imagens, as associações que os elementos presentes na imagem evocam, as expectativas do receptor, a resistência à análise, a presença ou ausência de comentários.

Para terminar, relata-se a experiência de análise de dois "cartoons» com forte conteúdo geográfico, feita por alunos do $9 .^{\circ}$ e do $11 .^{\circ}$ ano, extraem-se algumas conclusões e abrem-se novas pistas de trabalho.
\end{abstract}

Palavras-chave: Imagem, aprendizagem geográfica, representação, polissemia.

Abstract-Image Representation in Geographical Learning. The word «image» can convey countless different meanings. Of the «author-work-audience» trilogy, the study of the two former has traditionally been the object of the greatest attention, and only recently has the focus started to shift to the reception of the visual messages as well. Every message is liable to being interpreted in a variety of different ways, but this polysemic characteristic is especially important in the case of images. Every image is an analogy, a representation, of reality - one so «natural» that reality and its representation are often mistaken for one another. In order to avoid this erroneous superposition, it is necessary to move beyond recognition and into interpretation. Several factors are involved in the latter: some easily discernible, others considerably more obscure. These include the habit of looking at images, the associations evoked by the elements present in the image, the expectations of the recipient, the degree of resistance to analysis and the presence/absence of additional comments.

1 Investigadora do Centro de Estudos Geográficos da Universidade de Lisboa e Professora Associada da Faculdade de Ciências Sociais e Humanas, Universidade Nova de Lisboa. E-mail: mfalegria@netcabo.pt 
In conclusion, an account is rendered of carrying out an analysis of two cartoons with a strong geographical content with 9th and 11th grade students. This is used to draw a number of conclusions and suggest ideas for further research.

Key words: Image, geographical learning, representation, polysemy.

Résumé - INTERPRÉTATIONS DE L'IMAGE COMME OUTIL D'APPRENTISSAGE GÉOGRAPHIQUE. Au mot image s'associent un grand nombre de interprétations. De la trilogie auteur-oeuvre-public, ce sont les deux premiers aspects qui ont été le plus étudiés, encore que l'étude de la réception des images visuelles se soit développée récemment. Tout message est sujet à des interprétations diverses et cette polysémie concerne en particulier les images. L'image est une représentation ou analogie de la réalité, mais qui paraît si 'naturelle' à certains que ressemblance et identité se confondent pour eux. Afin d'éviter cette fausse superposition, il faut passer de la simple reconnaissance à l'interprétation. Celle-ci implique la conjonction de divers facteurs, dont les uns sont faciles à discerner mais d'autres plus obscurs, comme le degré d'habitude à observer des images, les associations d'idées évoquées par leurs éléments, l'expectative de qui les observe, la présence ou l'absence de commentaires en annexe.

On présente ensuite une expérience de l'analyse de deux cartoons à fort contenu géographique par des élèves de $9^{\text {ème }}$ et $11^{\text {ème }}$ années, qui permet de formuler quelques conclusions et pistes de recherche.

Mots-clés: image, apprentissage géographique, représentation, polysémie.

\section{INTRODUÇÃO}

O conhecimento sobre a interpretação das mensagens visuais ou audiovisuais é ainda escasso, quando comparado com o que existe sobre textos literários, apesar dos progressos realizados, sobretudo a partir da década de 1960, com a abordagem semiológica ${ }^{2}$.

Em Portugal, o Conselho Nacional de Educação e outras instituições educativas promoveram estudos sobre a «literacia» da população portuguesa, mas privilegiaram a palavra escrita e a oralidade ${ }^{3}$. Mais recentemente, têm-se

2 Muito simplificadamente semiologia é a ciência dos signos, que deve aos linguistas Saussure e Pierce as principais ideias, depois utilizadas em diversas formas de comunicação, não necessariamente a escrita e a oralidade. Há uma «Semiologia Gráfica», que diz respeito a mapas e gráficos (BERTIN, 1967), como há semiologias de outros tipos de imagem (ver bibliografia). No essencial, um signo diz respeito à associação entre um conceito (significante) e uma imagem linguística (significado); mais tarde foi introduzido o conceito de referente, ou seja, o objecto a que o conceito e o significado (verbal, gráfico, ou outro) se referem. Por exemplo a palavra "gato» é um conceito, um significante; o significado é a imagem que se associa à palavra, seja visual, gráfica, ou outra. O referente é o objecto que se pretende designar através deste conceito e de imagens que lhe estão associadas.

3 O Conselho Nacional de Educação promoveu em 1995 um Colóquio intitulado «A situação nacional da literacia», que desencadeou outros estudos, a maioria dos quais restringindo o uso da palavra à capacidade de ler, escrever e contar. Para uma explicação do vocábulo ver sobretudo 
desenvolvido pesquisas sobre a linguagem audiovisual, mas continuam a ser raras as preocupações didácticas. Nas poucas publicações com interesse pedagógico, dominam textos teóricos, com pouca ou nenhuma aplicação prática, preferencialmente dirigidos aos «media»e, sobretudo, à televisão. De facto, sabemos ainda muito pouco sobre a leitura de imagens, independentemente do suporte, o que se compreende se atendermos à evolução das interrogações semiológicas sobre a imagem.

$\mathrm{Na}$ história das ideias linguísticas, tomando esta palavra em sentido lato, descobrem-se duas perspectivas, remetendo uma para a lógica e outra para a retórica. Na primeira privilegia-se o estudo da obra em si, ao passo que na segunda se procuram perceber as intenções do autor e a sua recepção pelos leitores, entendidos estes mais como consumidores sociais, como um público no seio do qual se estabelecem determinadas relações, do que como leitores individuais.

Estas duas maneiras de encarar a triologia autor-obra-público são acompanhadas de uma determinada evolução recente. Imediatamente antes de 1960, e durante essa década, os estudos, nomeadamente no domínio artístico, incidiam sobretudo na obra como texto, entendendo a palavra no sentido lato de escritos, imagens diversas, fixas ou animadas, produtos audiovisuais, etc. A partir da década seguinte, com o humanista UMBERTo Eco e, sobretudo, com Hans RoBert Jauss, professor de literatura na Universidade de Constança ${ }^{4}$ procura ter-se em conta o jogo de interacções entre o autor, a obra e o público, dando contudo grande importância à recepção das mensagens, às diversas interpretações possíveis de uma dada obra, sobretudo das que incluem imagens. Mais recentemente, continuam a interessar as interpretações do público, mas procura-se enquadrá-las no contexto em que são recebidas, o que nem sempre tem sido conseguido, atendendo à multiplicidade de condições e situações psico-sociais e culturais.

Neste texto, depois de discutirmos alguns problemas gerais da leitura da imagem, analisaremos a interpretação de dois «cartoons» ${ }^{5}$, em certas condições de ensino da Geografia.

Dulce Rebelo (2003). Também o extinto Instituto da Biblioteca Nacional e do Livro promoveu pesquisas de natureza estatística sobre hábitos de Leitura (EDUARDo DE FreITAS et al., 1. a ed. 1997).

4 Não há trabalhos seus editados em Portugal, mas a sua obra está referenciada por MARTINNE JOLY (2003).

5 Não há uma boa tradução para esta palavra, pelo que se mantém a forma mais corrente. 


\section{ESPECIFICIDADE DA LEITURA DA IMAGEM}

A palavra «imagem» evoca um sem número de acepções ${ }^{6}$. O ponto comum entre elas parece ser, antes de mais o da analogia, ou seja, uma imagem é algo que se assemelha a qualquer coisa. Esta observação é válida tanto para as imagens mentais, como para as metáforas verbais, de que são exemplo entre tantas outras, as expressões «imagem de marca», «imagem de si», «imagem de uma profissão», aplicando-se também a mapas, fotografias, diapositivos, imagens televisivas, etc.

Uma consequência desse denominador comum é que a imagem pertence ao mundo das representações: se ela se assemelha a qualquer coisa é porque não é a própria coisa; evoca-a, por um processo de analogia. Outra consequência, que advém exactamente dessa semelhança, está no facto de a proximidade com o real poder fazer crer ao observador que está, de facto, perante uma realidade que é «natural».

Vários motivos concorrem para essa impressão de facilidade natural de leitura. Um deles está na rapidez de percepção visual, na simultaneidade de reconhecimento do conteúdo. Outro motivo reside na sua universalidade efectiva. Estamos rodeados de imagens, o que nem sequer é recente, e todos pensamos compreender as que percorrem o nosso quotidiano, pelo menos se se trata de imagens figurativas. Esta impressão de que as imagens se percebem fácil e naturalmente resulta da não distinção entre percepção e interpretação.

Ser capaz de identificar, de reconhecer, um conteúdo, um motivo figurativo, não significa que se compreenda a mensagem explícita ou implícita que ele contém. Perceber, no sentido de identificar, por um lado, e interpretar, por outro lado, são operações mentais com diferentes graus de complexidade, mesmo se, ou sobretudo se, temos a impressão de serem simultâneas.

Neste artigo consideramos a interpretação como uma operação mental que consiste em conferir sentido a um texto (escrito, figurativo ou de outro tipo), de atribuir um significado a algo que pode não estar visível, que pode não ser transparente e imediato, exigindo reflexão para se decifrar e compreender o que se observa, ou que o visível sugere. No caso da imagem, e sobretudo das imagens figurativas, esta aprendizagem é ainda mais necessária porque elas dão enfaticamente a ideia de «realidade» e de «naturalidade», e essa impressão acompanha-nos desde os primeiros anos de vida. Por outro lado, as imagens prestam-se a múltiplas leituras. Assim como existem diversos tipos de imagens, há várias maneiras de as interpretar, condicionadas por factores também variados.

6 Na comunicação que apresentei em Abril de 2004, no XVIII Encontro Nacional de Professores de Geografia, subordinado ao tema Geral «Geografia e Imagem», foram referidos alguns dos múltiplos conceitos da palavra «imagem», indicando-se bibliografia sobre o tema. Esta comunicação foi editada na revista Apogeo, número 27/28 de 2004. 
Entre os factores que condicionam a leitura há alguns facilmente perceptíveis, no quadro da civilização dita ocidental. Estão neste caso a falta de profundidade, a bidimensionalidade da maioria das imagens, a mudança de dimensões, a ausência de cheiro, de temperatura, às vezes de movimento. Mas há outros sobre os quais há que reflectir com mais cuidado. Referimo-nos àquilo a que Hans RoBert JaUSS chamou «horizonte de expectativas» e aos comentários, ou legendas, frequentemente associados às imagens ou que, estando ausentes, determinam, ainda assim, comentários linguísticos. Como dizia C. METz (1970), só há representação porque há linguagem; imagem e linguagem são indissociáveis.

A expressão «horizonte de expectativas», que pode ser entendida, de modo mais directo, como uma certa verdade esperada na leitura de imagens, apoia-se nas seguintes considerações:

Na triologia autor-obra-leitor, o último tem sido desvalorizado, como já se referiu. Ainda que a figura do destinatário esteja inscrita na própria obra (mesmo de modo vago), é mais importante o relacionamento do destinatário com obras anteriores, potencialmente semelhantes, que são tidas como exemplo.

A subjectividade de apreciação, o condicionamento pelo gosto pessoal tem de ser tido em conta, mas porventura tem maior pertinência a interacção entre o texto e o contexto institucional, ou seja, as condições de produção e, sobretudo, as de recepção das mensagens. Nessa recepção, não basta a análise de conteúdo de determinada imagem, para que haja interpretação. Há que ter em conta também os campos associativos ausentes, que os elementos presentes activam. De forma mais ou menos consciente, os elementos ausentes evocados pela mensagem perceptível intervêm no processo de compreensão das mensagens visuais. Dito de outra maneira: consegue compreender-se o que não se vê, a partir daquilo que se vê.

Se admitirmos que a imagem não é a realidade, mas uma forma de olhar a realidade, ou seja, uma representação visual culturalmente filtrada do real, que logo se articula com uma representação verbal, podemos falar de uma expectativa de verdade, de uma certa verdade-coerência, mas não de uma correspondência. Este ponto de vista legitima a afirmação de que a imagem não é verdadeira ou falsa em si mesmo. Sobre elas constroem-se interpretações, quase sempre condicionadas pelos comentários a elas associados.

As expectativas atribuídas às imagens são, de facto, frequentemente criadas pelo comentário (ou pela legenda) que as acompanha; não é apenas o visível que se associa à expectativa de verdade, mas o que se diz sobre ele. Os nossos hábitos culturais tendem a entronizar o comentário, como se a comunicação visual dependesse sobretudo dele. A manipulação da imagem, de que tanto se fala, poderá estar, nalguns casos, mais ligada ao discurso verbal do que ao icónico. HUdRISIER (citado por FERRONHA, 2001: 31) refere o seguinte paradoxo: vivemos num mundo de inflação de imagens e pensamos sempre debaixo do poder do texto. 
Para Porcher (1972), o texto tem em relação à figura duas funções: a de âncora e a de substituição. A primeira, consiste em indicar «o bom nível de leitura», o que decorre da inevitável polissemia da imagem. É a sugestão do que deve ser privilegiado, entre a diversidade possível de interpretações. A função de substituição ocorre quando a mensagem linguística complementa carências expressivas da imagem, tornando-se sua substituta, pelo menos do ponto de vista de quem construiu o comentário, ou a legenda, ou ainda quando estão inevitavelmente ausentes indicações precisas de lugar, de tempo, de duração ou de falas das personagens ${ }^{7}$.

Outro aspecto da especificidade da leitura de imagens diz respeito ao próprio processo de análise. Para Joly (2003) as análises de imagens são muitas vezes consideradas tanto como uma redução inevitável do pensamento e do prazer visual, como um mal necessário para a pedagogia. A autora reconhece, porém, que em nenhum caso essas análises conseguem dar conta nem da riqueza, nem da complexidade da experiência visual. A análise da imagem e a necessária verbalização que a acompanha não podem, evidentemente, restituir a experiência visual na sua globalidade. No entanto, se circunscrevermos as expectativas que temos dessa apreciação linguística, podemos considerá-la um exercício rico, não só do ponto de vista pedagógico, como para uma melhor fruição estética.

Embora não haja um método universal de análise, Joly (2003) considera que há três componentes essenciais a reter: a execução da análise; as resistências à própria análise e a forma como a encaramos; enfim, as suas funções.

A «execução da análise» é um modo particular de recepção, que se distingue das formas espontâneas, por ser um trabalho de observação orientada. A observação está ligada à ideia de prazer, de júbilo, enquanto ao trabalho se associa o esforço, o pesar. Enquanto trabalho, a análise está reservada ao especialista e eventualmente ao pedagogo, não ao espectador vulgar, que mantém a seu respeito um certo número de resistências.

Estas resistências são alimentadas por outras, também elas ligadas a oposições ideológicas. Além da oposição lazer/«trabalho» há a «sentir» versus «entender», que também contribui para rejeitar a análise das obras visuais como um atentado à arte «intocável». Analisar e interpretar seriam, assim, actividades que se oporiam ao próprio prazer estético, receio, aliás, às vezes manifestado pelos estudantes quando se aborda a análise da imagem.

Outro aspecto tem a ver com resistências à análise, traduzidas na inutilidade e no risco. A análise da imagem seria inútil, porque a imagem é considerada uma linguagem universal. Com efeito, a aparente «naturalidade» da leitura das imagens, pelo menos das figurativas, leva a pensar que a sua análise e estudo são supérfluos, tanto mais que essas imagens parecem reconhecíveis por

7 Porque a presença ou ausência de legenda, ou de comentário de uma imagem, pode ser pedagogicamente explorada, foi feita uma tentativa com os «cartoons» apresentados, a que nos referiremos. 
todos e em qualquer lugar. Há nesta afirmação uma parcela de verdade, mas não toda a verdade porque, por um lado, as pessoas que não têm o hábito de as observar desde a infância não reconhecem as transformações necessárias à representação visual (redução, ausência de volume ou de cor, etc.); por outro lado "reconhecer» não quer dizer "entender»; é preciso passar da identificação das formas, à interpretação, uma etapa suplementar na compreensão.

Piaget (1956) distingue claramente a percepção, que diz respeito ao reconhecimento dos objectos na sua presença, da representação, que os evoca, mesmo na sua ausência. Qualquer representação é um acto de criação fundado na aparência; é uma forma de apreensão do mundo, pessoal e subjectiva, acompanhada de uma certa dose de imaginação. As nossas representações apoiam-se na aparência dos objectos, no significado que lhes atribuímos, e não nos objectos em si. A representação, sobretudo na era da imagem, exige não só que se conheçam os símbolos de uma dada sociedade, como o contexto cultural da comunicação visual, para se passar do icónico ao simbólico, da denotação à conotação ${ }^{8}$.

Para terminar, as referências às funções da análise, poderíamos dizer que, se desejarmos que a experiência estética não seja, de forma nenhuma, oposta ao agir (como trabalho), podemos admitir que a análise consegue preencher várias funções, que são necessárias, ou pelo menos úteis, a uma interpretação mais acabada: satisfazer o gosto; cumprir uma função criativa e também uma função didáctica. É a esta que agora nos vamos referir.

\section{A INTERPRETAÇÃO DE «CARTOONS»POR ALUNOS DO 9. ${ }^{\circ}$ E DO $11 .^{\circ}$ ANO}

No $2 .^{\circ}$ período de ano lectivo de 2002/2003 e no $1 .^{\circ}$ período do ano lectivo seguinte, foi solicitado a alunos de três escolas da área de Lisboa a análise dos «cartoons» reproduzidos (fig. 1 e 2). A amostra envolveu 53 alunos de 3 turmas do $9 .^{\circ}$ ano (turmas, D, E e 3) e 60 alunos $^{9}$ de 4 turmas do $11 .^{\circ}$ ano (turmas H1, H2, 9 e 11).

Claro que a selecção de imagens foi ponderada tendo em consideração alguns factores, que não vamos comentar, mas apenas enumerar: a imensidão da escolha, o tipo de suporte, a facilidade de reprodução, os programas escolares, a cor, a dimensão geográfica implícita ou explícita.

8 A denotação diz respeito à identificação do visível numa imagem, daquilo que objectivamente ela figura, enquanto a conotação tem a ver com associações potenciais que a leitura permite, com a mensagem oculta que o visível permite atingir.

9 No $9 .^{\circ}$ ano, 52 alunos analisaram a figura 2 e no $11 .^{\circ}$ ano 59 alunos. As diferenças entre o número de alunos que analisaram cada figura no mesmo ano têm a ver com o facto de o exercício ter sido feito em dias diferentes, faltando alguns alunos. 
Os objectivos apresentados por escrito aos professores das turmas envolvidas foram os seguintes: «Identificar dificuldades na interpretação escrita de imagens simbólicas; analisar as respostas escritas sobre essas imagens e a atribuição de títulos; comparar as interpretações de alunos do $9 .^{\circ}$ ano com as de alunos do $11 .^{\circ}$ ano; relacionar as interpretações com as classificações obtidas pelos alunos, em Geografia e nas outras disciplinas».

As instruções que acompanhavam as figuras, reproduzidas numa folha A4, eram muito simples: numa dada aula distribuía-se a figura 1 e na aula seguinte a figura 2. Sob cada figura estava escrita a frase: «Diz por palavras tuas como interpretas a figura». Na base da página, solicitava-se: «Agora atribui um título à figura» ${ }^{10}$. Foram facultados cerca de 15 minutos para cada aluno interpretar por escrito a figura e lhe atribuir um título, sem qualquer ajuda do docente. No caso de haver perguntas, ou comentários orais eles deviam ser registados ${ }^{11}$.

Os quadros elaborados para apuramento da interpretação das figuras são demasiado extensos para serem reproduzidos, pelo que se apresentam apenas alguns quadros síntese.

Se reproduzirmos os títulos a que correspondem interpretações das figuras que foram classificadas com Bom ou Muito Bom, temos as comparações que os quadros I e II mostram. Tendo em conta que este tipo de exercício era novidade para todas as turmas, podemos considerar que há bastante coerência e imaginação nalguns dos títulos atribuídos, sobretudo no $11 .^{\circ}$ ano.

No 9. ${ }^{\circ}$ ano são excepção (do meu ponto de vista) os títulos da figura $1 \mathrm{com}$ os números 4 e 9. Das 11 «boas» interpretações desta figura, 7 pertencem aos alunos da melhor turma do $9 .^{\circ}$ ano e apenas 4 às outras duas turmas (quadro III). A ideia de forte relação entre bons alunos e boas interpretações é reforçada pela seguinte contagem: os 11 «bons» alunos das 3 turmas do 9. ${ }^{\circ}$ ano (nota de 3 ou mais em Geografia e média a todas as disciplinas de 2,5 ou superior) tiveram todos, excepto um, «boas» interpretações da figura 1; dos 27 alunos fracos ou razoáveis (classificações inferiores às indicadas), apenas 7 tiveram interpretações consideradas «razoáveis», não atingindo nenhum deles o «bom» ${ }^{12}$.

10 Quando a experiência foi iniciada compararam-se interpretações destas imagens com e sem título, atribuídos previamente. Para a figura 1 sugeriu-se o seguinte: «Pare, pare! Sem árvores a Terra não sobrevive»; para a figura 2: «Primário contra Secundário, ou talvez não...». A análise dos comentários dos alunos não provou que eles fossem mais ricos e consistentes quando era sugerido um título. Talvez a explicação resida na simplicidade das figuras, na familiaridade do tema e no tipo de títulos, muito curtos, sem acrescentarem nada de novo à imagem. Quanto às pequenas modificações metodológicas que esta primeira tentativa acarretou não nos vamos deter nelas, pois não têm qualquer importância.

11 O único comentário que me chegou, repetido por vários alunos, dizia respeito ao facto de na figura 2 uma parte da imagem ser «negra» e outra «branca».

12 Registaram-se casos raros de alunos que não assinaram, pelo que não foi possível comparar as interpretações com as classificações. Nestes casos os alunos não levaram o exercício a sério. Exemplo de títulos da figura 2: «Os dois anormais»; «Um desenho muito feio». 
Quadro I - Títulos atribuídos à figura 1 a que correspondem interpretações boas ou muito boas

Table I-Titles given to figure 1 that correspond to good or very good interpretations

\begin{tabular}{|c|c|}
\hline $\begin{array}{c}9^{\circ} \text { ano: } 49 \text { respostas, } 11 \text { delas }(23 \%) \text { com boas } \\
\text { interpretações }\end{array}$ & $\begin{array}{c}11 .^{\circ} \text { ano: } 49 \text { respostas, } 20 \text { delas }(41 \%) \text { com boas } \\
\text { ou muito boas interpretações }\end{array}$ \\
\hline 1. «Destruição do meio ambiente» & 1. «Parem a destruição, senão...» \\
\hline 2. "Cuide da natureza e viverá mais tempo» & $\begin{array}{l}\text { 2. "Pavimentaram o Paraíso e colocaram um parque de } \\
\text { estacionamento" }\end{array}$ \\
\hline 3. «A terra e as árvores» & 3. "As raízes do mundo estão em perigo» \\
\hline 4. «A destruição que está nas nossas mãos» & $\begin{array}{l}\text { 4. "A contribuição dos jovens para um desenvolvimento } \\
\text { sustentável» }\end{array}$ \\
\hline 5. «Pare! Não destrua a terra» & 5. «Destruição mundial» \\
\hline 6. "Um futuro péssimo» & 6. "S.O.S. mundo em perigo» \\
\hline 7. «Sem árvores não há vida» & 7. «Destruição maciça das florestas e do planeta azul» \\
\hline 8. «Não, não as derrubem» & 8. "A destruição do nosso planeta» \\
\hline 9. "Dia mundial da árvore sem abusos ambientalistas" & 9. «De que lado estás?» \\
\hline 10. «O homem destruidor» & 10. «Cada vez mais próximo ...» \\
\hline \multirow[t]{10}{*}{ 11. "Acabem com a desflorestação» } & 11. «Será que não vêem a função da natureza!?!? \\
\hline & 12. "Luta pela salvação do planeta» \\
\hline & 13. "A incompetência ambiental do homem» \\
\hline & 14. «Pare! Pela sua sobrevivência!» \\
\hline & 15. «Pare! Um a um podemos tornar o mundo diferente» \\
\hline & $\begin{array}{l}\text { 16. "Destruição das árvores e do solo. (Destruição da } \\
\text { natureza)» }\end{array}$ \\
\hline & 17. «O império da tecnologia sobre o ambiente» \\
\hline & 18. «A betonização do solo» \\
\hline & 19. "A vida depende de uma simples árvore. Não a \\
\hline & 20. «Como o homem tem destruído o mundo» \\
\hline
\end{tabular}

Quadro II - Títulos atribuídos à figura 2 a que correspondem interpretações boas ou muito boas

Table II - Titles given to figure 2 that correspond to good or very good interpretations

\begin{tabular}{|c|c|}
\hline $\begin{array}{c}9 .^{\circ} \text { ano: } 49 \text { respostas, } 6 \text { delas }(12 \%) \text { com boas } \\
\text { interpretações }\end{array}$ & $\begin{array}{c}11 .^{\circ} \text { ano: } 44 \text { respostas, } 16 \text { delas }(36 \%) \text { com boas } \\
\text { ou muito boas interpretações }\end{array}$ \\
\hline 1. «A diferença dos países» & 1. «Norte e sul, branco e preto» \\
\hline 2. "As nacionalidades mudam as economias» & $\begin{array}{l}\text { 2. «Um mundo, dois hemisférios - dominantes e domi- } \\
\text { nados» }\end{array}$ \\
\hline 3. «Os diferentes mundos» & $\begin{array}{l}\text { 3. «Dualismo mundial - os problemas do desenvolvi- } \\
\text { mento» }\end{array}$ \\
\hline 4. «Mundos completamente diferentes» & 4. «Dois mundos num só» \\
\hline 5. «A tecnologia dos P.D. e dos P.V.D.» & 5. «Mundos opostos» \\
\hline \multirow{11}{*}{$\begin{array}{l}\text { 6. "As diferenças entre pessoas e civilizações a nível } \\
\text { mundial» }\end{array}$} & 6. «Contrastes económicos que dividem o mundo» \\
\hline & 7. «Países desenvolvidos vs países em desenvolvimento» \\
\hline & 8. "A desigualdade de actividades a nível mundial» \\
\hline & 9. «Contraste semi-global» \\
\hline & 10. «Contraste entre dois hemisférios» \\
\hline & 11. "Dois sectores, uma única finalidade» \\
\hline & 12. «Separar o inseparável» \\
\hline & 13. «Desigualdades dividem o nosso mundo» \\
\hline & 14. «O mundo dos dois mundos» \\
\hline & 15. "As duas faces da moeda" \\
\hline & 16. «O mundo dividido em dois» \\
\hline
\end{tabular}




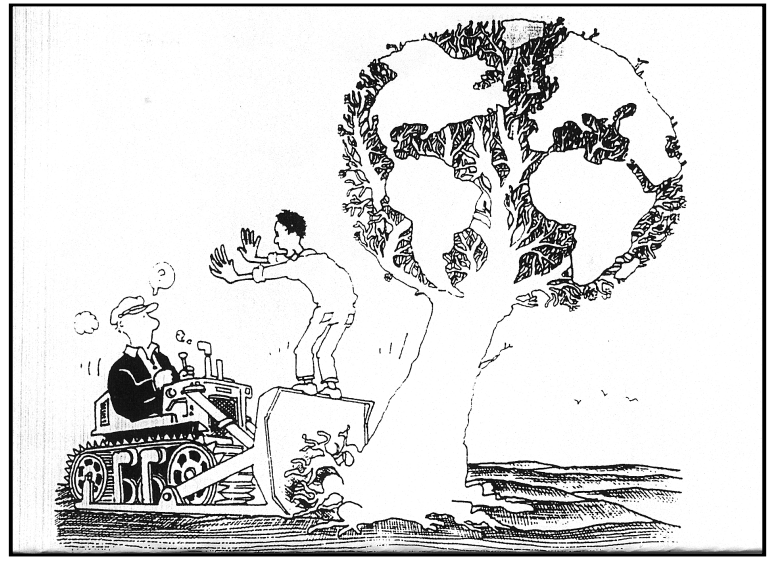

Fig. 1 - Imagem sem título interpretada por alunos do $9 .^{\circ}$ e do $11 .^{\circ}$ ano

Fig. 1 -Picture (without title) to be interpreted by $9^{\text {th }}$ and $11^{\text {th }}$ grade students

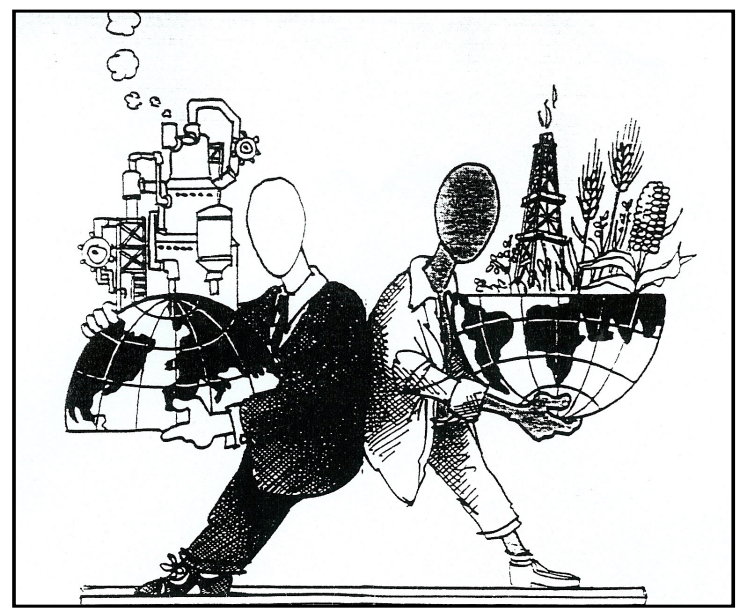

Fig. 2 - Imagem sem título interpretada por alunos do $9 .^{\circ}$ e do $11 .^{\circ}$ ano

Fig. 2 -Picture (without title) to be interpreted by $9^{\text {th }}$ and $11^{\text {th }}$ grade students

No $11 .^{\circ}$ ano os títulos são sugestivos e alguns mesmo muito imaginativos. Há 6 «Muito Boas» interpretações, sendo 4 «Boas» na turma dos melhores alunos e 11 «Boas» apreciações nas turmas piores, não havendo nestas nenhum «Muito bom» (quadro III). No conjunto das 4 turmas do $11 .^{\circ}$ ano houve 23 interpretações consideradas «Boas» ou «Muito Boas», sendo apenas 5 os alunos que não atingiram média de 14 em Geografia e nas outras disciplinas. 
$\mathrm{Na}$ análise da figura 2 os resultados não são muito diferentes. No conjunto há títulos aceitáveis no $9 .^{\circ}$ ano e algumas interpretações boas, enquanto no $11 .^{\circ}$ ano há mais títulos sugestivos e melhores interpretações (quadro II).

Os quadros III e IV resumem a qualidade dos textos interpretativos. Ressalta claramente que nas turmas menos boas do $9 .^{\circ}$ ano os textos são no geral fracos, quando muito razoáveis (cerca de $80 \%$ dos alunos na figura $1 \mathrm{e}$ $96 \%$ na figura 2). Na melhor turma do $9 .^{\circ}$ ano há $47 \%$ de «Boas» interpretações da figura 1 e $33 \%$ da figura 2 . No $11 .^{\circ}$ ano os resultados da análise são, no conjunto, nitidamente melhores. Registe-se apenas que na interpretação da figura 1, nas turmas melhores, as «Boas» $\mathrm{e}$ «Muito Boas» interpretações chegam aos $50 \%$; na figura 2 elas ultrapassam os $62 \%$.

Quadro III - Síntese das interpretações da figura 1 por alunos do $9 .^{\circ}$ e do $11 .^{\circ}$ ano

Table III - Synthesis of the interpretations of Figure 1 by $9^{\text {th }}$ and $11^{\text {th }}$ grade students

\begin{tabular}{|c|c|c|c|c|c|c|c|c|}
\hline \multirow{3}{*}{$\begin{array}{l}\text { Avalia o do texto } \\
\text { Interpretativo }\end{array}$} & \multicolumn{4}{|c|}{$9 \ldots$ ano } & \multicolumn{4}{|c|}{$11 \ldots$ ano } \\
\hline & \multirow{2}{*}{$\begin{array}{r}\text { Turmas fracas (1) } \\
\text { Total }\end{array}$} & \multicolumn{3}{|c|}{ Turmas m dias (2) } & \multirow{2}{*}{$\begin{array}{c}\text { Turmas fracas (3) } \\
\text { Total }\end{array}$} & \multicolumn{3}{|c|}{ Turmas m dias (4) } \\
\hline & & $\%$ & Total & $\%$ & & $\%$ & Total & \\
\hline Fraco & 19 & 55,9 & 1 & 6,6 & 7 & 17,9 & 0 & 0 \\
\hline Razo vel & 11 & 32,3 & 7 & 46,7 & 21 & 53,8 & 10 & 50,0 \\
\hline Bom & 4 & 11,8 & 7 & 46,7 & 11 & 28,3 & 4 & 20,0 \\
\hline M. Bom & 0 & 0 & 0 & 0 & 0 & 0 & 6 & 30,0 \\
\hline Total & 34 & 100 & 15 & 100 & 39 & 100 & 20 & 100 \\
\hline
\end{tabular}

(1) Média das classificações 2,2 e 2,5, nas turmas 3 e E; (2) Média das classificações 2,9, turma D; (3) Média das classificações 12,5, 11, 6 e 11,7, turmas 9, 11 e H2; ${ }^{(4)}$ Média das classificações 14,3, turma 3.

Quadro IV - Síntese das interpretações da figura 2 por alunos do $9 .^{\circ}$ e do $11 .^{\circ}$ ano

Table IV-Synthesis of the interpretations of Figure $2^{\text {th }}$ and $9^{\text {th }}$ grade students

\begin{tabular}{|c|c|c|c|c|c|c|c|c|}
\hline \multirow{4}{*}{$\begin{array}{l}\text { Avaliação do texto } \\
\text { Interpretativo } \\
\text { Fraco }\end{array}$} & \multicolumn{4}{|c|}{$9 .^{\circ}$ ano } & \multicolumn{4}{|c|}{$11^{\circ}$ ano } \\
\hline & \multicolumn{2}{|c|}{ Turmas fracas (1) } & \multicolumn{2}{|c|}{ Turmas médias (2) } & \multicolumn{2}{|c|}{ Turmas fracas (3) } & \multirow{2}{*}{\multicolumn{2}{|c|}{$\begin{array}{l}\text { Turmas médias (4) } \\
\text { Total }\end{array}$}} \\
\hline & Total & $\%$ & Total & $\%$ & Total & $\%$ & & \\
\hline & 22 & 71,0 & 3 & 20,0 & 7 & 24,1 & 0 & 0 \\
\hline Razoável & 8 & 25,8 & 7 & 46,7 & 14 & 48,4 & 6 & 37,5 \\
\hline Bom & 1 & 3,2 & 5 & 33,3 & 7 & 24,1 & 8 & 50,0 \\
\hline M. Bom & 0 & 0 & 0 & 0 & 1 & 3,4 & 2 & 12,5 \\
\hline Total & 31 & 100 & 15 & 100 & 29 & 100 & 16 & 100 \\
\hline
\end{tabular}

(1) Média das classificações 2,2 e 2,5, nas turmas 3 e E; (2) Média das classificações 2,9, turma D; (3) Média das classificações 12,5, 11, 6 e 11,7, turmas 9, 11 e H2; (4) Média das classificações 14,3, turma 3. 
Quadro V - Títulos e comentários à figura 1 de alunos com médias baixas (2,2-2,5 no $9 .^{\circ}$ ano e $11,5-12,5$ no $11 .^{\circ}$ ano) e comentários «fracos»

Table $V$-Titles and comments to Figure 1 by poorly-performing students (average grades 2,2-2,5 in the $9^{\text {th }}$ grade and 11,5-12,5 in the 11 $1^{\text {th }}$ grade) and «poor» comments

\begin{tabular}{|c|c|}
\hline $\begin{array}{c}9 .^{\circ} \text { ano } \\
\text { Títulos e interpretações «fracas» }\end{array}$ & $\begin{array}{c}11 .^{\circ} \text { ano } \\
\text { Títulos e interpretações «fracas» }\end{array}$ \\
\hline $\begin{array}{l}\text { N. }{ }^{\circ} 44-« O s \text { ambientalistas são fundamentalistas» } \\
\text { Comentário: «Um ambientalista a matar-se por uma } \\
\text { árvore.» }\end{array}$ & $\begin{array}{l}\text { N. }{ }^{\circ} 53 \text { - «Um crime florestal» } \\
\text { Comentário: «Acho que a figura } 1 \text { retrata a revolta do } \\
\text { agricultor ao saber que a sua propriedade será } \\
\text { destruída, provavelmente para construção de infraes- } \\
\text { truturas.» }\end{array}$ \\
\hline $\begin{array}{l}\mathrm{N} .^{\circ} 51-\text { - } 5 \text { Dia mundial da árvore» } \\
\text { Comentário: «Um lavrador a derrubar uma árvore.» }\end{array}$ & $\begin{array}{l}\text { N. }{ }^{\circ} 55 \text { - «Por cada árvore que é derrubada ta-se a } \\
\text { destruir uma pequena parte da nossa terra» } \\
\text { Comentário: É um agricultor a derrubar uma árvore } \\
\text { com um representação de home (?) na parte superior } \\
\text { vê-se também um homem em cima da máquina a } \\
\text { tentar impedir a acção destruidora do agricultor.» }\end{array}$ \\
\hline
\end{tabular}

Nos quadros V a VIII transcrevem-se textos de 2 alunos de cada ano. Começa-se pelos comentários «fracos» à figura 1 (quadro V), para depois se mostrarem «bons» exemplos de interpretações da mesma figura (quadro VI). O processo é repetido na figura 2 (quadros VII e VIII).

Estes textos, e outros não reproduzidos, são interessantes a vários títulos e merecem algumas apreciações quanto à dimensão, à correcção linguística e discursiva, à natureza dos factos registados e, enfim, aos estereótipos que se detectam.

A dificuldade de elaborar comentários com alguma clareza é muito mais nítida no $9 .^{\circ}$ ano. No geral os textos dos alunos deste ano são curtos, sem dizerem necessariamente o essencial. Neste ano são também mais frequentes do que no $11 .^{\circ}$ ano os erros ortográficos, as incorrecções na pontuação e na construção das frases e o egocentrismo da interpretação («na minha opinião», «eu penso que», etc.).

Quanto à substância do conteúdo, a riqueza e pertinência das ideias é nitidamente melhor no $11 .^{\circ}$ ano. Na análise da figura 1 vários alunos do $11 .^{\circ}$ ano perceberam a árvore como símbolo global (no 9. ${ }^{\circ}$ ano só dois alunos associaram a árvore à Terra), fazendo notar que o seu derrube significa outras perdas. Ou seja, no $9 .^{\circ}$ ano predominaram leituras «denotativas», havendo no $11 . .^{\circ}$ ano casos de "conotação» evidentes. Raros alunos registaram a surpresa do condutor do tractor. 
Quadro VI - Títulos e comentários à figura 1 de alunos com médias elevadas (2,9 no $9 .^{\circ}$ ano e 14,3 no $11 .^{\circ}$ ano) e comentários «bons»

Table VI-Titles and comments to Figure 1 by highly-performing students (average 2,9 in the $9^{\text {th }}$ grade and 14,3 in the $11^{\text {th }}$ grade) and "good" comments

\section{9. ${ }^{\circ}$ ano \\ Títulos e interpretações «boas»}

N. ${ }^{\circ} 21$ - «Cuide da natureza e viverá mais tempo» Comentário: «Na minha opinião a figura interpreta a preocupação que se deve ter com as árvores e as plantas em geral, porque sem elas não há oxigénio e sem oxigénio os seres humanos e os animais não sobrevivem.»

\section{N. ${ }^{\circ} 24$ - «Pare! Não destrua a terra»}

Comentário: «A árvore tem representada na sua copa o Mundo e está a ser arrancada por uma máquina. Isto significa que o Mundo sem árvores e sem plantas e «coisas» naturais não pode existir. As plantas estão a ser derrubadas e têm mais interesse para as pessoas que não vêem a importância do meio ambiente.»

\section{$11 .^{\circ}$ ano \\ Títulos e interpretações «boas»}

N. ${ }^{0} 10$ - «Destruição mundial»

Comentário: «A figura 1 é uma alusão à destruição de florestas e às consequências que tal evento pode trazer. Esta imagem significa que, ao arrancar as árvores, isto é, ao destruir a vegetação, o nosso mundo, o próprio planeta que está representado na copa da árvore, será igualmente destruído.

O facto da árvore estar só na figura e o cenário ser um deserto infinito implica que aquela é a última árvore do mundo e, por isso, o sustenta, como última esperança da continuação da vida no planeta. A imagem apela à salvação da Terra e a um maior cuidado com a vegetação, principalmente as florestas, como indica o homem que está em cima da pá do tractor.»

N. ${ }^{\circ} 28$ - «Luta pela salvação do planeta»

Comentário: «A imagem mostra-nos genericamente a luta da humanidade pela salvação do planeta. Particularmente vemos um homem a guiar uma máquina para destruir uma árvore e um rapaz a tentar impedi-lo. A árvore representa o mundo, uma vez que a destruição de árvores é um grande problema actual, e consequentemente também o é a destruição do planeta; sem árvores não existe oxigénio, e sem oxigénio não existe vida.

Assim, interpreto a imagem como sendo a luta pela sobrevivência do planeta.»

Apenas no $11 .^{\circ}$ ano os alunos foram capazes de chamar a atenção, na figura 2, para a presença de plataformas de petróleo, sem que a propriedade desse bem se traduza em vantagens para os habitantes, que são equiparados a outros do hemisfério Sul. Enquanto no $9 .^{\circ}$ ano a principal oposição é entre «brancos»e «pretos», bem e mal vestidos, no $11 .^{\circ}$ ano os alunos reconhecem que se defrontam duas economias, ressaltando os riscos ambientais da industrialização. É evidente que esta figura se presta a dicotomias simplistas, que os programas de Geografia infelizmente cultivam.

Quadro VII - Títulos e comentários à figura 2 de alunos com médias baixas e comentários «fracos» 
Table VII-Titles and comments to figure 2 by poorly-performing students and «poor» comments

\begin{tabular}{|c|c|}
\hline $\begin{array}{c}9 .^{\circ} \text { ano } \\
\text { Títulos e interpretações «fracas» }\end{array}$ & $\begin{array}{c}11 .^{\circ} \text { ano } \\
\text { Títulos e interpretações «fracas» }\end{array}$ \\
\hline $\begin{array}{l}\mathrm{N} .^{\circ} 25-« \mathrm{O} \text { mundo a sua volta» } \\
\text { Comentário: «A figura quer dizer que o mundo tanto } \\
\text { pertence a brancos como a pretos de varias formas.» }\end{array}$ & $\begin{array}{l}\text { N. }{ }^{\circ} 43 \text { - «Diferenciação das actividades agrícolas» } \\
\text { Comentário: «Dois homens encostados um ao outro. } \\
\text { Cada um tem uma metade do globo. Em cima de uma } \\
\text { das metades do homem que tá bem vestido e é branco } \\
\text { está a meu ver a agricultura representada com uma } \\
\text { tecnologia avançada em contrário do homem preto } \\
\text { que tem uma agricultura mais rural e está mal } \\
\text { vestido.» }\end{array}$ \\
\hline $\begin{array}{l}\text { N. }{ }^{\circ} 27 \text { - «O lado mau e o lado bom» } \\
\text { Comentário: «Vejo um branco a destruir o mundo.» }\end{array}$ & $\begin{array}{l}\text { N.o } 55 \text { - «Evolução» } \\
\text { Comentário: «Representação do mundo dividido em } \\
\text { dois: o hemisfério norte mecanizado funciona como } \\
\text { (?); África, o hemisfério sul portador de riquezas mas } \\
\text { não mecanizado.» }\end{array}$ \\
\hline
\end{tabular}

\section{CONCLUSÃO}

Os textos que os alunos construíram sobre estas duas figuras reconstituem apenas uma parte do que elas lhes sugeriram, porque a expressão linguística não consegue traduzir a globalidade de significados de uma imagem. Além disso, as dificuldades de expressão escrita são notórias, sobretudo nos alunos mais novos.

Apesar da simplicidade e do esquematismo destes «cartoons» há naturalmente elementos ausentes que os traços presentes evocam e toda uma aprendizagem geográfica anterior que é trazida à superfície, às vezes com bastante propriedade. É compreensível que a interpretação seja mais rica nos alunos com mais anos de escolaridade mas, como vimos, há outra relação a estabelecer: os melhores alunos são claramente os que conseguem atribuir títulos mais pertinentes e sugestivos e os que expressam em textos relativamente correctos, ricos e com substância, as ideias principais expressas pelas mensagens icónicas.

De acordo com MESSARIs (citado por DamásIo, 2001: 131) «a interpretação do sentido correcto de uma imagem audiovisual não está dependente de uma literatura específica de leitura dessa mesma imagem, mas antes pelo contrário de uma literacia de base - literacia da língua escrita - possuída previamente pelo sujeito». Nesta frase seriam de retirar as palavras "correcto» (não há

Quadro VIII - Títulos e comentários à figura 2 de alunos com médias elevadas e comentários «bons» 
Table VIII - Titles and comments to Figure 2 by highly-performing students and "good» comments

\section{$9^{\circ}$ ano \\ Títulos e interpretações «boas»}

N. ${ }^{\circ} 5$ - «Os diferentes mundos»

Comentário: «Esta figura quer dizer que na maioria, os países desenvolvidos estão no Hemisfério Norte e os subdesenvolvidos no Hemisfério Sul. Na figura da esquerda está um homem branco (que predomina nos PD), que está a agarrar como se o possui-se o Hemisfério Norte e por cima estão máquinas. Na figura do lado está um homem de cor (que predomina nos PVD) que está a segurar como se o possui-se, o hemisfério Sul, e por cima cereais e coisas simples sem desenvolvimento.»

N. ${ }^{\circ} 6$ - «Mundos completamente diferentes»

Comentário: "São dois tipos de mundo, ou seja, do lado esquerdo é um mundo mais desenvolvido com máquinas; todos os tipos de trabalho são baseados nas máquinas e a figura do lado direito é um mundo que está em desenvolvimento ou seja todos os tipos de trabalho é feito tudo à base das «mãos»; é tudo mais trabalhado com as mãos.»
$11 .^{\circ}$ ano

Títulos e interpretações «boas»

N. ${ }^{\circ} 1$ - «Norte e Sul, branco e preto»

Comentário: «O homem branco representa a maioria da população do hemisfério norte, o qual ele segura nas mãos. Este hemisfério é maioritariamente industrializado, tal como se pode ver pelos mecanismos em cima do globo.

O homem preto representa a população do hemisfério sul, em que a característica é a abundância de petróleo, e de agricultura tal como está representado em cima do hemisfério sul do globo.»

N. ${ }^{\circ} 8$ - «Dualismo mundial - os problemas do desenvolvimento»

Comentário: «Esta figura revela muito bem o dualismo que existe entre hemisfério Norte e hemisfério Sul.

No hemisfério Norte predomina o desenvolvimento industrial e tecnológico, uma sociedade baseada no consumo.

Por outro lado, no hemisfério Sul continuamos a deparar com uma contradição do desenvolvimento: a par com uma agricultura de subsistência confrontamo-nos com a implementação de plataformas e refinarias de petróleo nos países com mais carências. O problema mais grave é o facto de esta extracção de petróleo não desenvolver o país onde se situa, mas o país de origem da empresa petrolífera.»

apenas um sentido e muito menos um que seja correcto) e «audiovisual» pois a dificuldade de ler imagens é maior se não houver discurso oral associado.

A experiência feita deixa muitos caminhos abertos. Por exemplo, estabelecer relações entre hábito de ler imagens e qualidade da interpretação linguística, entre meio cultural e propriedades da interpretação, entre condições de recepção e tipo de leitura. Neste caso, em que todos estiveram sujeitos a condições formais de ensino semelhantes e dispuseram do mesmo tempo, o que é determinante na recepção da mensagem, há indícios claros de que:

a) Há uma nítida melhoria da interpretação de imagens do $9 .^{\circ}$ para o $11 .^{\circ}$ ano; 
b) As melhores interpretações coincidem maioritariamente com os bons alunos em todas as disciplinas, incluindo a Geografia;

c) Parece haver capacidades inexploradas na interpretação de imagens, bem expressas no conjunto de títulos atribuídos e nalguns comentários que, muito provavelmente, indiciam hábitos de interpretar imagens cultivados fora da escola.

Enfim, parte dos pressupostos teóricos avançados na parte inicial do texto ficam empiricamente provados, o que é ainda pouco frequente em investigações pedagógicas sobre a imagem.

\section{BIBLIOGRAFIA}

Alegria, M. F. (1999) - Visões Geográficas na Banda Desenhada. VIII Colóquio Ibérico de Geografia, Actas, Vol. I, Lisboa: 440-447.

Alegria, M. F. (2001) - Contributos para uma prática da leitura de imagens fixas. La Formación Geográfica de los Ciudadanos en el Cambio del Milenio, Universidad Complutense de Madrid, Associación de Geógrafos Españoles, Associação de Professores de Geografia, Madrid: 351-359.

Alegria, M. F. (2003) - Ensinar Geografia numa sociedade mediática. Revista da Faculdade de Letras - Geografia, I série, XIX, Porto: 11-24.

Aguaded Gómez, J. I. (2003) - Educar en la Sociedad de la Televisión. Saberes e Práticas na Formação de Professores e Educadores. Actas das Jornadas DCILM 2002, Universidade do Minho, Braga: 13-29.

Bailly, A. (1992) - Les représentations en Géographie. In A. Bailly et al., ed. Encyclopédie de Géographie. Economica, Paris: 371-385.

Balle, F. (2003) - Os media. Campo das Letras, Porto.

BARTHES, R. (1989) - Elementos de semiologia. Ed. 70, Lisboa.

BERTIN, J. (1972) - Sémiologie graphique. Ed. Mouton, Paris.

Benavente, A.; Ponte, J. P. (1989) - A escola e os audiovisuais. Departamento de Educação da Faculdade de Ciências da Universidade de Lisboa, Lisboa.

CALAdo, I. (1991) - A imagem na comunicação pedagógica. Coimbra (dissertação de doutoramento, polic.).

CARrilho, M.; et al. (org., 2002) - Novos média, novas politicas? Debate sobre a sociedade de informação. Celta, Oeiras.

Coppen, H. (1982) - Utilización didáctica de los medios audiovisuales. Ed. Anaya, Madrid.

DamÁsıo, M. J. (2001) - Práticas educativas e novos media. Ed. Minerva, Coimbra.

Daveau, S. (1984) - Visão do mundo, televisão e ensino da Geografia. Finisterra - Revista Portuguesa de Geografia, XIX(38): 252-256.

Decaigny, T. (1976) - Communication audio-visuelle et pédagogie. 2. ${ }^{\mathrm{a}}$ ed., F. Nathan, Paris.

De Freitas, E. et al. (1997) - Hábitos de leitura. Um inquérito à população portuguesa. Dom Quixote, Lisboa. 
Eco, H. (1990) - O signo. 4. ${ }^{\text {a }}$ ed., Editorial Presença, Lisboa.

Eco; H. et al. (1969) - Los efectos de las comunicaciones de masas. Ed. Jorge Alvarez. Madrid.

FERIN, I. (2002) - Comunicação e culturas do quotidiano. Quimera Editores, s. l.

Ferronha, A. L. (2001)-Linguagem audiovisual. Pedagogia com a imagem. Pedagogia da imagem. Ed. Elo, Mafra.

Fiske, J. (1993) - Introdução ao estudo da comunicação. Ed. Asa, Porto.

FreitAs, C. et al. (1997) - Tecnologias de Informação e Comunicação na Aprendizagem. Instituto de Inovação Educacional, Lisboa.

Giacomantonio, M. (1986) - Os meios audiovisuais. Ed. 70, Lisboa.

Giacomantonio, M. (1986) - O ensino através dos meios audiovisuais. Ed. Summus, São Paulo.

JACQUinOT, G. (1985) - L'école devant les écrans. Les Éditions E S F, Paris.

JoLY, M. (1994) - Introdução à análise da imagem. Ed. 70, Lisboa.

Joly, M. (2003) - A imagem e a sua interpretação. Ed. 70, Lisboa.

Martin, M. (1982)-Sémiologie de l'image et pédagogie. Pour une pédagogie de la recherche. P.U.F., Paris.

Metz, C. (1970) - Au-delà de l'analogie, l'image. Communications, 15: 1-10.

Metz, C. (1970) - Images et Pédagogie. Communications, 15: 161-167.

Miranda, A. (2003)-Ciência da Informação. Teoria e metodologia de uma área em expansão. Thesaurus Editora, Brasília.

McLhuan, M. (1964)-Pour comprendre les média. Les prolongements technologiques de l'homme. Editions du Seuil, Paris.

MolEs, A. (1981) - L'Image Communication Fonctionnelle. Casterman, Tournai.

Mondada, L.; Racine, J-B. (1992) - Géographie et semio-linguistique. In A. Bailly et al., ed. Encyclopédie de Géographie. Economica, Paris: 257-272.

Mota, I. De La (1988) - Función social de la información. Ed. Paraninfo. Madrid.

Piaget, J; Inhelder, B. (1956) - The Child's Conception of Space. Routledge, London.

Porcher, L. (1972) - La photographie et ses usages pédagogiques. A. Colin, Paris.

Porcher, L. (1977) - A escola paralela. Livros Horizonte, Lisboa.

Rebelo, D. (2003) - Literacia e linguagem da imagem. Literacia, Linguagem, Ciências e Tecnologia., Universidade Aberta, Lisboa (CD-Rom, 7 p. n.n).

Roda Salinas, F. J.; Beltrán De Tena, R. (1988) - Información y Comunicación. Los medios y su aplicación didáctica. Editorial Gustavo Gili, Barcelona.

Rodriguez IllerA, J. L. (1988) - Educación y Comunicación. Ed. Paidós, Barcelona.

Rodrigues, A.D. et al. (1981) - Comunicação Social e Jornalismo. 1. ${ }^{\circ}$ Volume. O Fabrico da Actualidade. Ed. A Regra do Jogo, Lisboa.

Vilches, L. (1997) - La Lectura de la Imagen. Prensa, Cine, Televisión. 7. a ed., Paidós Comunicación, Barcelona. 